\title{
Severe chronic pain following spinal cord damage: a pragmatic perspective for prescribing opioids
}

\author{
Peter Wayne New (iD) $1,2,3,4$
}

Received: 14 May 2018 / Revised: 30 May 2018 / Accepted: 30 May 2018

(C) International Spinal Cord Society 2018

\begin{abstract}
The controversial issue of prescribing opioids to people with spinal cord damage who have severe pain is discussed in this paper. The reasons for concern regarding the increase in opioid prescription over recent years are outlined, along with a summary of the major potential adverse outcomes associated with opioids, such as falls, respiratory suppression, adverse endocrine effects, cognitive impairment, and the potential for opioid abuse, addiction and death. Situations when opioids are more appropriate are considered to be in the immediate post-trauma or post-operative periods. More controversial is the use of opioids in chronic non-cancer pain. A brief review of the evidence regarding opioids in chronic non-cancer pain is presented, and strategies outlined for reducing the risk of adverse consequences from opioid use in chronic non-cancer pain. These strategies include considerations before starting opioids, during initiation, monitoring activities and the cessation process. A vital consideration before starting opioids includes ensuring that all alternatives to opioids have been fully considered and trialled. Finally, some pragmatic proposals for prescribing opioids in people with SCD are suggested. It is recommended that before opioids are commenced, that the informed consent process should be complimented by a treatment agreement, with an initial 4-week trial period, and close monitoring of established goals.
\end{abstract}

This point-counterpoint of Spinal Cord Series and Cases highlights the contentious attitudes regarding opioid prescribing currently confronting clinicians treating people with severe pain and spinal cord damage (SCD). Opinions and options regarding the vexatious and challenging issue of opioid prescribing for these patients are offered by Kertesz and Manhapra [1], and Bryce [2].

The paper by Kertesz and Manhapra [1] focuses on issues regarding the weaning of opioids. They assert that opioids should be gradually weaned to $90 \mathrm{mg} /$ day or less in

$\triangle$ Peter Wayne New

p.new@alfred.org.au

1 Spinal Rehabilitation Service, Caulfield Hospital, Alfred Health, Melbourne, Victoria, Australia

2 Principal Researcher, Epworth-Monash Rehabilitation Medicine Unit, Monash University, Melbourne, Victoria, Australia

3 Department of Epidemiology and Preventive Medicine, School of Public Health \& Preventive Medicine, Monash University, Melbourne, Victoria, Australia

4 Department of Medicine, Rehabilitation and Aged Services Program, Monash Health, Melbourne, Victoria, Australia patients experiencing harm in excess of definite benefit and in other patients who agree. They highlight the potential for adverse consequences from compelling people to wean off opioids, particularly without their consent.

Bryce [2] highlights reasons for not commencing opioids in people with chronic pain after SCD. He also advocates the weaning of opioids in people taking these agents, especially in those on higher doses, emphasizing the association between the risks of harm associated with higher doses.

In this summary, I will highlight the reasons for concern regarding the increase in opioid prescription over recent years, when opioids are appropriate to consider, along with when they are more controversial, briefly review the evidence for efficacy of opioids in chronic pain, and highlight some strategies for reducing the risk of adverse consequences from opioid use in people with SCD.

\section{Background}

In recent years there has been growing concern regarding an epidemic of misuse of opioids. The opioid epidemic has probably been greatest in the USA, where it is reported that the cost to the economy in 2015 was $\$ 504$ billion [3], and 
that opioids were associated with the deaths of over 42,000 people, five times as many as in 1999 [4]. Opioid misuse is also recognised as a major problem in other countries, including Australia [5] and Canada [6].

Safety concerns regarding the use of opioids include falls, respiratory suppression, adverse endocrine effects, cognitive impairment, opioid-induced hyperalgesia, and the potential for abuse, addiction and death [7, 8].

Important principles of medical practice include the relief of suffering, improving quality of life and the ethical doctrine of primum non nocere (first, do no harm), all of which are central considerations regarding the prescription of opioids. In this context, there is little doubt regarding the appropriateness of opioids in patients with severe pain following an acute injury, in the early post-operative period, or as part of the palliative care of people with cancer or other terminal illnesses. The appropriateness of opioid use, however, becomes much murkier when it comes to its' use in people with chronic non-cancer pain, such as occurs following spinal cord damage (SCD) [9, 10].

Pain is a common complication in people with traumatic spinal cord injury (SCI) $[11,12]$ and non-traumatic SCD, many of these people have troublesome chronic pain [13], and many of whom are potential candidates for opioids.

\section{Summary of evidence for opioids in chronic non-cancer pain}

The use of opioids in chronic non-cancer pain has been the subject of considerable research. Unfortunately, many of the randomised trials in this area were funded by the pharmacological industry and tend to report short-term outcomes.

A 2009 Cochrane review of opioids in people with chronic non-cancer pain due to osteoarthritis concluded that small to moderate improvements in pain are outweighed by the large increase in adverse events, and that they should not be routinely used, even for severe osteoarthritis pain [14]. Study of long-term benefits from opioids is challenging, and the findings inconclusive. A systematic review of randomised trials of opioids for chronic non-cancer pain with a minimum of 12 weeks follow-up reported that the effectiveness of tramadol for osteoarthritis was borderline, and for all other opioids and pain conditions there was poor evidence of effectiveness [15]. A Cochrane review from 2010 of long-term opioids ( $>6$ months treatment) identified very few quality studies (only one randomised trial), with many participants discontinuing treatment because of side-effects or inadequate pain relief, with the authors concluding that the evidence for pain relief was weak, and the evidence for quality of life or functional benefit was inconclusive [16].

Of relevance to people with SCD, and in contrast to the above, meta-analyses and reviews of opioids in neuropathic 
pain have found efficacy for these agents [17-19]. This is important, because about half the people with SCD experience neuropathic pain [20]. Guidelines for the management of neuropathic pain, however, emphasise that opioids are only third-line or fourth-line agents because of their potential adverse effects [21-23].

\section{Strategies for reducing the risk of adverse consequences from opioid use in chronic non-cancer pain}

It is important to consider that even among people taking opioids for chronic non-cancer pain with no previous substance abuse, misuse of opioids is reported to occur in over a third of patients [24]. Misuse includes taking higher dosages than recommended or using opioids to treat stress or insomnia.

A number of guidelines and reviews have covered the use of opioids in chronic non-cancer pain [7, 8, 25-27]. and pain in SCD [11, 28, 29]. Strategies have been proposed to mitigate the risk of adverse consequences from opioid use in chronic non-cancer pain [7, 8, 25-27]. These strategies include considerations before starting opioids, during initiation, monitoring activities and the cessation process (Table 1). A vital consideration before starting opioids includes ensuring all alternatives to opioids have been fully considered and trialled. Similarly, it is important to determine the classification of pain, whether nociceptive, neuropathic or both, in order to ensure that non-opioid pharmacological options for neuropathic pain have been fully explored. Among the considerations suggested when prescribing opioids is the use of an opioid treatment agreement [7, 30-34], which I will elaborate on further in the following section.

\section{Pragmatic proposals for prescribing opioids in people with spinal cord damage}

In people with acute traumatic SCI opioids are appropriate to use for severe pain in the early period after onset for fracture or surgery-related pain. Opioids may also be needed during the acute management of people with non-traumatic SCD following surgery related to their underlying aetiology.

It is recommended that the medical team closely monitor pain control in the weeks following the onset of SCD. It is also important to note that pain can develop some time following the onset of SCD, and if severe, opioids may be initiated by other medical staff besides those in rehabilitation. In the post-acute period (e.g. 2-6 weeks) following the onset of SCD, people already prescribed opioids should have the need for these reviewed by their treating medical team, with a view to a trial of weaning these when clinically indicated. This is a role that the rehabilitation physician (physiatrist) caring for the patient can and should be involved with. The process of weaning should be gradual, with reductions every 4-14 days, depending on the dose reduction, withdrawal symptoms and change in pain perception. A challenge and risk arise when people with SCD are discharged from hospital still on opioids that have only recently been commenced following the onset of SCD. The patients' primary care doctor (general practitioner) may not have the confidence or expertise necessary for appropriately weaning opioids. It is suggested that for all patients discharged from hospital on recently commenced opioids that the discharge summary includes specific detailed suggestions regarding the recommended approach for weaning the opioids, or for reviewing the need to consider weaning.

In the post-acute and chronic phases following the onset of SCD, patients may be prescribed opioids in a number of situations, and may be considered for these agents when they fail to respond to more conservative pain management strategies. These situations include muscular-skeletal problems, such as shoulder pain from overuse, injuries from falls, comorbid health conditions that are exacerbated during rehabilitation (e.g. arthritis) or the delayed onset of neuropathic pain, where there is better evidence of efficacy compared with nociceptive pain. Therefore, it is very important to classify the type of pain in people with SCD, as it influences the goal setting and informed consent aspects of considering opioid prescription. It is essential to recall that because of their potential adverse effects and risks of harm, opioids are only third-line or fourth-line agents for neuropathic pain, and that the other agents and strategies should be considered before opioids [12, 21, 23].

Given the complexities of using opioids in people with $\mathrm{SCD}$, to achieve the best outcomes, including minimizing the risk of harm, it is vital that doctors follow the strategies for reducing the risk of adverse consequences from opioid use in chronic non-cancer pain, outlined above. In implementing these, informed consent should be complimented by a treatment agreement and plan, with an initial 4-week trial period, and close monitoring of established goals. Although the evidence that treatment agreements prevent opioid misuse is lacking [35], they provide a useful framework when establishing informed consent, the goals of trialling opioids for pain management and indications for weaning opioids. Furthermore, the patients' primary care doctor should be fully informed of the use of the treatment contract, and may even take over the monitoring of it after discharge from inpatient rehabilitation.

When patients are in the community, having opioids prescribed by only one medical practitioner can potentially reduce the risk of misuse. A strategy that can enhance and facilitate this is a state-based, or (ideally) national, real-time prescription monitoring system that record all opioid- 
prescription requests, so that 'doctor-shopping' can theoretically be stopped. Such a system is currently in the process of being implemented in Victoria, Australia [36].

Furthermore, given the limited evidence and risks associated with opioid use, additional well-designed, multicentre trials are needed regarding the use of opioids, including in people with SCD, that are not sponsored by pharmaceutical companies.

\section{Compliance with ethical standards}

Conflict of interest The authors declare that they have no conflict of interest.

\section{References}

1. Kertesz SG, Manhapra A. The drive to taper opioids: mind the evidence, and the ethics. Spinal Cord Ser Cases. 2018.

2. Bryce TN. Opioids should not be prescribed for chronic pain after SCI. Spinal Cord Ser Cases. 2018.

3. President's Council of Economic Advisors. The underestimated cost of the opioid crisis. Nov 2017. p. Available at https://www. whitehouse.gov/sites/whitehouse.gov/files/images/TheUnderestimated\%Cost $\%$ of $\%$ the $\%$ Opioid\%Crisis.pdf.

4. Centers for Disease Control. Drug overdose data, 2016, Available at https://www.cdc.gov/drugoverdose/data/statedeaths.html.

5. Carter JS. Opioid prescription crisis: Everyday Aussies, not 'doctor shoppers', at heart of crisis, experts say. 2017, Available at http://www.abc.net.au/news/2017-11-21/doctorshoppers-not-atheart-of-prescription-opioid-crisis/9167606.

6. A province-by-province look at opioid-overdose stats, including fentanyl. Global News. 17 Nov 2016, Available at http://globa lnews.ca/news/3072316/a-province-by-province-look-at-opioidoverdose-stats-including-fentanyl/. (accessed 2018 Apr. 7).

7. Freynhagen R, Geisslinger G, Schug SA. Opioids for chronic noncancer pain. BMJ. 2013;346:f2937.

8. Chou R, Turner JA, Devine EB, Hansen RN, Sullivan SD, Blazina I, et al. The effectiveness and risks of long-term opioid therapy for chronic pain: a systematic review for a National Institutes of Health Pathways to Prevention workshop. Ann Intern Med. 2015;162:276-86.

9. Katz NP, Birnbaum HG, Castor A. Volume of prescription opioids used nonmedically in the United States. J Pain Palliat Care Pharmacother. 2010;24:141-4.

10. Kuehn BM. Opioid prescriptions soar: increase in legitimate use as well as abuse. JAMA. 2007;297:249-51.

11. Bryce TN, Budh CN, Cardenas DD, Dijkers M, Felix ER, Finnerup NB, et al. Pain after spinal cord injury: an evidence-based review for clinical practice and research: report of the National Institute on Disability and Rehabilitation Research Spinal Cord Injury Measures meeting. J Spinal Cord Med. 2007;30:421-40.

12. Hagen EM, Rekand T. Management of neuropathic pain associated with spinal cord injury. Pain Ther. 2015;41:51-65.

13. Dijkers M, Bryce T, Zanca J. Prevalence of chronic pain after traumatic spinal cord injury: a systematic review. J Rehabil Res Dev. 2009;46:13.

14. Nuesch E, Rutjes AW, Husni E, Welch V, Jüni P. Oral or transdermal opioids for osteoarthritis of the knee or hip. Cochrane Database Syst Rev. 2009;4:CD003115.

15. Manchikanti L, Ailinani H, Koyyalagunta D, Datta S, Singh V, Eriator I, et al. A systematic review of randomized trials of long- term opioid management for chronic non-cancer pain. Pain Physician. 2011;14:91-121.

16. Noble M, Treadwell JR, Tregear SJ, Coates VH, Wiffen PJ, Akafomo $\mathrm{C}$, et al. Long-term opioid management for chronic noncancer pain. Cochrane Database Syst Rev. 2010;1:CD006605.

17. Finnerup NB, Sindrup SH, Jensen TS. The evidence for pharmacological treatment of neuropathic pain. Pain. 2010;150: $573-81$.

18. Hollingshead J, Dühmke RM, Cornblath DR. Tramadol for neuropathic pain. Cochrane Database Syst Rev. 2006;3:CD003726.

19. Eisenberg E, McNicol E, Carr DB. Opioids for neuropathic pain. Cochrane Database Syst Rev. 2006;3:CD006146.

20. Burke D, Fullen BM, Stokes D, Lennon O. Neuropathic pain prevalence following spinal cord injury: a systematic review and meta-analysis. Eur J Pain. 2017;21:29-44.

21. Freynhagen R, Bennett MI. Diagnosis and management of neuropathic pain. BMJ. 2009;339:b3002.

22. National Institute for Health and Clinical Excellence. Neuropathic pain: the pharmacological management of neuropathic pain in adults in non-specialist settings. (Clinical guideline 173). 2018. Available at nice.org.uk/guidance/cg173 (accessed 2018, June 16th)

23. Guy SD, Mehta S, Casalino A, Côté I, Kras-Dupuis A, Moulin DE, et al. The CanPain SCI clinical practice guidelines for rehabilitation management of neuropathic pain after spinal cord: recommendations for treatment. Spinal Cord. 2016;54(Suppl 1):S14-23.

24. Grattan A, Sullivan MD, Saunders KW, Campbell CI, Von Korff MR. Depression and prescription opioid misuse among chronic opioid therapy recipients with no history of substance abuse. Ann Fam Med. 2012;10:304-11.

25. Chou R, Fanciullo GJ, Fine PG, Adler JA, Ballantyne JC, Davies $\mathrm{P}$, et al. Clinical guidelines for the use of chronic opioid therapy in chronic noncancer pain. J Pain. 2009;10:113-30.

26. Dowell D, Haegerich TM, Chou R. CDC guideline for prescribing opioids for chronic pain-United States, 2016. JAMA. 2016;315:1624-45.

27. Busse JW, Craigie S, Juurlink DN, Buckley DN, Wang L, Couban $\mathrm{RJ}$, et al. Guideline for opioid therapy and chronic noncancer pain. CMAJ. 2017;189:E659-E66.

28. Teasell RW, Mehta S, Aubut JA, Foulon B, Wolfe DL, Hsieh JT, et al. A systematic review of pharmacologic treatments of pain after spinal cord injury. Arch Phys Med Rehabil. 2010;91:816-31.

29. Mehta S, McIntyre A, Janzen S, Loh E, Teasell R, Spinal Cord Injury Rehabilitation Evidence Team. Systematic review of pharmacologic treatments of pain after spinal cord injury: an update. Arch Phys Med Rehabil. 2016;97:1381-91.

30. Fishman SM, Bandman TB, Edwards A, Borsook D. The opioid contract in the management of chronic pain. J Pain Symptom Manag. 1999;18:27-37.

31. Jacobson PL, Mann JD. The valid informed consent-treatment contract in chronic non-cancer pain: its role in reducing barriers to effective pain management. Comp Ther. 2004;30:101-4.

32. Hariharan J, Lamb GC, Neuner JM. Long-term opioid contract use for chronic pain management in primary care practice. A five year experience. J Gen Intern Med. 2007;22:485-90.

33. Cheatle MD, Savage SR. Informed consent in opioid therapy: a potential obligation and opportunity. J Pain Symptom Manag. 2012;44:105e16.

34. Tobin DG, Forte KK, McGee SJ. Breaking the pain contract: a better controlled-substance agreement for patients on chronic opioid therapy. Clev Clin J Med. 2016;83:827-35.

35. Rager JB, Schwartz PH. Defending opioid treatment agreements: disclosure, not promises. Hastings Cent Report. 2017;47:24-33.

36. Department of Health \& Human Services. SafeScript: State Government Victoria; [cited 2018 19th April]. Available from: https://www2.health.vic.gov.au/public-health/drugs-and-poisons/ safescript. 